\title{
Stress distribution on dentin-cement-post interface varying root canal and glass fiber post diameters. A three-dimensional finite element analysis based on micro-CT data
}

\author{
Priscilla Cardoso LAZARI' ${ }^{1}$, Rodrigo Caldeira Nunes de OLIVEIRA ${ }^{2}$, Rodolfo Bruniera ANCHIETA ${ }^{1}$, Erika Oliveira de \\ ALMEIDA ${ }^{1}$, Amilcar Chagas FREITAS JUNIOR ${ }^{3}$, Sidney KINA ${ }^{1}$, Eduardo Passos ROCHA ${ }^{1}$
}

\author{
1- Department of Dental Materials and Prosthodontics, Araçatuba Dental School, Univ. Estadual Paulista, Araçatuba, SP, Brazil. \\ 2- São Leopoldo Mandic, Campinas, SP, Brazil. \\ 3- School of Health Sciences, Potiguar University - UnP, Natal, RN, Brazil.
}

Corresponding address: Eduardo Passos Rocha - Faculdade de Odontologia de Araçatuba - UNESP - Departamento de Materiais Odontológicos e Próteses - Rua Jose Bonifacio, 1193 - 16015-050 - Araçatuba - SP - Brasil -Phone: +55-18-36363290 - e-mail: eduardo_rocha@foa.unesp.br

Submitted: February 27, 2013 - Modification: June 19, 2013 - Accepted: August 23, 2013

\section{ABSTRACT}

\begin{abstract}
bjective: The aim of the present study was to analyze the influence of root canal and glass fiber post diameters on the biomechanical behavior of the dentin/cement/post interface of a root-filled tooth using 3D finite element analysis. Material and Methods: Six models were built using micro-CT imaging data and SolidWorks 2007 software, varying the root canal $(C)$ and the glass fiber post $(P)$ diameters: $C 1 P 1-C=1 \mathrm{~mm}$ and $P=1 \mathrm{~mm}$; $\mathrm{C} 2 \mathrm{P} 1-\mathrm{C}=2 \mathrm{~mm}$ and $\mathrm{P}=1 \mathrm{~mm} ; \mathrm{C} 2 \mathrm{P} 2-\mathrm{C}=2 \mathrm{~mm}$ and $\mathrm{P}=2 \mathrm{~mm} ; \mathrm{C} 3 \mathrm{P} 1-\mathrm{C}=3 \mathrm{~mm}$ and $\mathrm{P}=1 \mathrm{~mm}$; $\mathrm{C} 3 \mathrm{P} 2-\mathrm{C}=3 \mathrm{~mm}$ and $\mathrm{P}=2 \mathrm{~mm}$; and $\mathrm{C} 3 \mathrm{P} 3-\mathrm{C}=3 \mathrm{~mm}$ and $\mathrm{P}=3 \mathrm{~mm}$. The numerical analysis was conducted with ANSYS Workbench 10.0. An oblique force (180 N at $45^{\circ}$ ) was applied to the palatal surface of the central incisor. The periodontal ligament surface was constrained on the three axes $(x=y=z=0)$. Maximum principal stress $\left(\sigma_{\max }\right)$ values were evaluated for the root dentin, cement layer, and glass fiber post. Results: The most evident stress was observed in the glass fiber post at C3P1 (323 MPa), and the maximum stress in the cement layer occurred at C1P1 (43.2 MPa). The stress on the root dentin was almost constant in all models with a peak in tension at C2P1 (64.5 MPa). Conclusion: The greatest discrepancy between root canal and post diameters is favorable for stress concentration at the post surface. The dentin remaining after the various root canal preparations did not increase the stress levels on the root.
\end{abstract}

Key words: Dental pins. Dental cements. Finite element analysis. Tooth root. Post and core technique.

\section{INTRODUCTION}

The reestablishment of function through direct and/or indirect restorations in endodontically treated teeth remains a challenge ${ }^{11,19}$. Several studies have demonstrated reduced resistance to failure in teeth that are endodontically treated ${ }^{8}$.

Tooth architecture is modified during endodontic treatment as a result of caries removal, access to the canal, and instrumentation in the root canal ${ }^{17}$. All these factors are associated with the higher internal stress induced in these teeth since this force is directly proportional to the fracture resistance and volume of the remaining dental structure ${ }^{12}$. This fact becomes critical when excessive reduction of the thickness of the root canal walls occurs as a result of severe caries, over-instrumentation, previous restoration with large-diameter posts, or internal root resorptions ${ }^{30}$. These characteristics may increase the risk of fracture in these teeth relative to teeth with more pulp vitality ${ }^{23}$.

The biomechanics of the endodontically treated teeth are also influenced since the insertion of intraradicular posts, such as cast metal or prefabricated 
posts, modifies the mechanical behavior of the tooth and the distribution of the masticatory efforts ${ }^{1,23}$.

According to some authors, a high number of vertical fractures are observed in roots with metallic posts with a high elastic modulus that distribute and concentrate stress in the apical third of the $\operatorname{root}^{11,20,28}$. Thus, the use of intra-radicular posts with an elastic modulus similar to dentin, such as glass fiber posts, promotes better stress distribution in the remaining dental structure and along the cementation interface ${ }^{7,28}$. In addition, it has been suggested that the use of these posts with a resin cement increases the fracture resistance of the

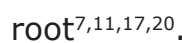

Another important factor is the reduced root fracture susceptibility when using these posts, since fracture of the post or cementation interface may occur prior to root fracture, allowing of restoration of the tooth ${ }^{29}$. However, despite all these benefits of glass fiber posts (GFP), their selection and indication are still not fully understood ${ }^{23}$. Little information exists regarding the selection of glass fiber post diameter for use in flared root canals ${ }^{8,18}$. For example, it is unclear whether a large- or smalldiameter post should be used with large diameter canals ${ }^{1,5,7,8}$.

Recent studies show that bonding of the post to the root canal occurs mainly by friction retention, and micromechanical interlocking via the hybrid layer occurs only in the coronal third of the root ${ }^{10}$. Furthermore, the cement film thickness should be carefully evaluated when deciding the post diameter. Higher stresses can occur during cement curing, mainly because the C-Factor in the canal can exceed 200, compromising the bond strength ${ }^{25}$.

The aim of the present study was to evaluate the stress behavior of the adhesive interface in the root canal of a non-vital maxillary central incisor restored with a ceramic crown, varying the root canal and the glass fiber post diameters. The following hypotheses were tested: 1 - The discrepancy between the post and root canal diameters does not increase the stress level on the post interface; 2 - The stress on the remaining root is directly proportional to the increase in root canal diameter, regardless of the post used.

\section{MATERIAL AND METHODS}

This study was approved by the Human Research Ethics Committee at the School of Dentistry of Araçatuba, Univ. Estadual Paulista - UNESP (process \#2008/01845). A right maxillary central incisor from the human tooth bank at the Department of Dental Materials and Prosthodontics was used to build the models.

Based on a micro-computed tomography image $(\mu \mathrm{CT})$, a total of 720 slices were obtained after tooth scanning (CT40, Scanco Medical, Bassersdorf, Switzerland). For reconstruction of the solid model, 82 slices were serially selected for tridimensional reconstruction using SolidWorks 2007 software (SolidWorks Corp., Concord, MA, USA). These included all the structures of the natural tooth (enamel, crown and root dentin, dental pulp, and periodontal ligament) ${ }^{4,21}$.

Based on the previous methodology, six geometric models were built. In all models, the tooth was considered as root-filled with a glass fiber post inserted, and the remaining crown was restored with a core and an all-ceramic crown of feldspathic ceramic.

The canal diameter varied $(\mathrm{C} 1=1 \mathrm{~mm} ; \mathrm{C} 2=2$ $\mathrm{mm}$; $\mathrm{C} 3=3 \mathrm{~mm}$ ) while the glass fiber post diameter remained constant $(1 \mathrm{~mm})$ to evaluate the influence of root canal diameter (C) on stress distribution in the dentin-cement-post interface (Figure 1).

To evaluate the influence of the glass fiber post diameter $(P)$ on stress distribution in the dentin/ cement/post interface, we varied the post diameter ( $\mathrm{P} 1=1 \mathrm{~mm} ; \mathrm{P} 2=2 \mathrm{~mm} ; \mathrm{P} 3=3 \mathrm{~mm}$ ) while the canal diameter remained constant (D3=3 mm) (Figure 1 ).

The tooth reduction and the periodontal ligament thickness $(0.25 \mathrm{~mm})$ were comparable in all models. The major differences between the models were root canal diameter, glass fiber post diameter, and thickness of the cementation interface.

After the elaboration of the models, the files were transferred to the finite element software in IGES format (ANSYS Inc., Canonsburg, PA, USA) to determine the regions and generate the finite element mesh.

The mechanical properties [Elastic modulus (E) and Poisson's ratio (v)] were obtained from specific

\begin{tabular}{|c|c|}
\hline Models & Description \\
\hline C1P1 & Root canal and glass fiber post with 1 mm of diameter \\
\hline C2P1 & Root canal with $2 \mathrm{~mm}$ of diameter and glass fiber post with $1 \mathrm{~mm}$ of diameter \\
\hline C3P1 & Root canal with $3 \mathrm{~mm}$ of diameter and glass fiber post with $1 \mathrm{~mm}$ of diameter \\
\hline C2P2 & Root canal with $2 \mathrm{~mm}$ of diameter and glass fiber post with $2 \mathrm{~mm}$ of diameter \\
\hline C3P2 & Root canal with $3 \mathrm{~mm}$ of diameter and glass fiber post with $2 \mathrm{~mm}$ of diameter \\
\hline C3P3 & Root canal with $3 \mathrm{~mm}$ of diameter and glass fiber post with $3 \mathrm{~mm}$ of diameter \\
\hline
\end{tabular}

Figure 1- Description of the models with different root canal $(C)$ and glass fiber post $(P)$ diameters 
literature (Table 1) 5,21,22, considering isotropic, homogeneous, and linearly elastic parameters. All structures in these models were considered perfectly integrated ${ }^{5}$.

The periodontal ligament surface was fixed on $x$, $y$ and $z$ axes for all models $(x=y=z=0)$. A distributed load of $180 \mathrm{~N}$ was applied to the lingual surface of the tooth, in $45^{\circ}$ angulation to the tooth's long axis for all models (Figure 2) 27 .

In order to achieve the convergence of analysis $(6 \%)^{4,21}$, the mesh was composed of tetrahedral elements of $0.2 \mathrm{~mm}$ in size. The models had up to

Table 1- Mechanical properties of the materials, elastic modulus (E) and Poisson ratio (v)

\begin{tabular}{lcc}
\hline \multicolumn{1}{c}{ Material } & E (GPa) & v \\
\hline Dentin $^{21}$ & 18.6 & 0.31 \\
Periodontal ligament $^{21}$ & $6.9 \times 10-5$ & 0.45 \\
\hline Gutta-percha $^{21}$ & $1.4 \times 10-1$ & 0.45 \\
Glass fiber post $^{5}$ & 40 & 0.30 \\
Enamel $^{21}$ & 80 & 0,33 \\
Feldspathic ceramic $^{23}$ & 69 & 0.30 \\
Composite resin $^{5}$ & 12 & 0.30 \\
Resin cement $^{5}$ & 8 & 0.30 \\
\hline
\end{tabular}

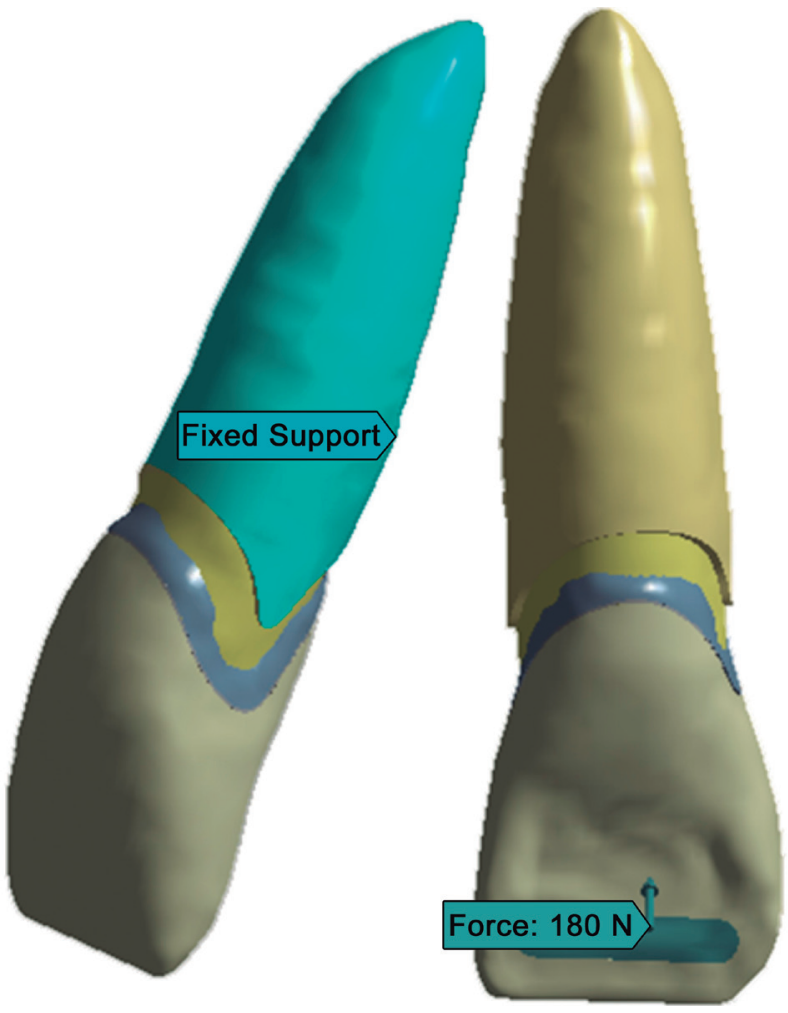

Figure 2-As a boundary condition, the external surface of the periodontal ligament was constrained (left), $y=x=z=0$. A load of $180 \mathrm{~N}$ was applied to a specific area at the lingual surface of the crown, $45^{\circ}$ to the tooth's long axis (right)
267,091 elements and 423,719 nodes (Figure 3 ).

Maximum principal stress $\left(\sigma_{\max }\right)$ values were evaluated for the root dentin, cement layer, and glass fiber post. According to, these analysis criteria are appropriate for predicting failures in non-ductile materials, such as dentin and cement layers ${ }^{1,3,16}$.

\section{RESULTS}

Variation of the root canal diameter (1, 2, and $3 \mathrm{~mm}$ ) with a constant glass fiber post diameter of $1 \mathrm{~mm}$

Different behaviors of the glass fiber post and the cementation interface for a range of root canal

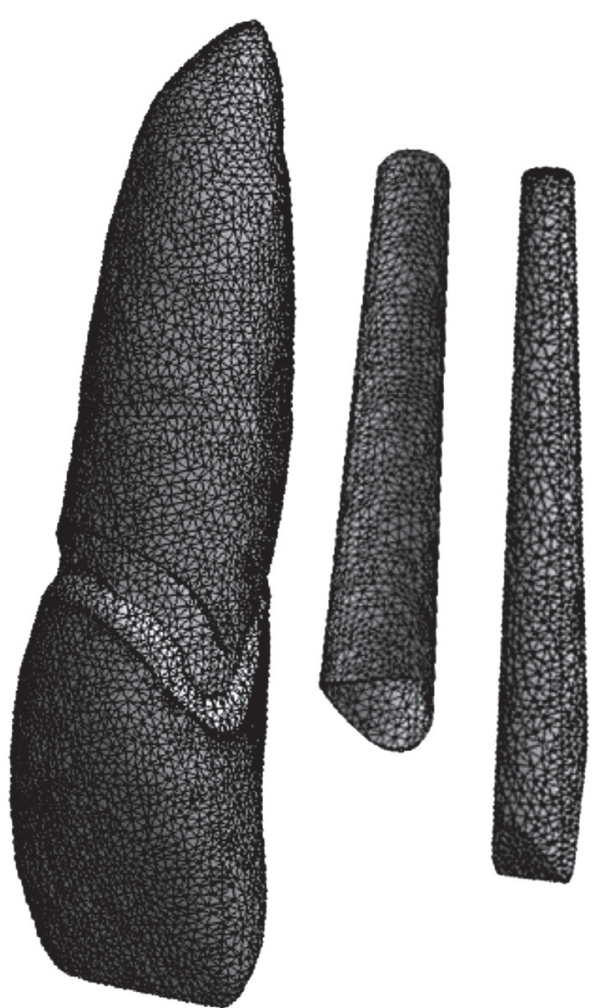

Figure 3- Finite element mesh of the teeth structures. Root dentin (left); Cement line (middle); Glass fiber post (right)

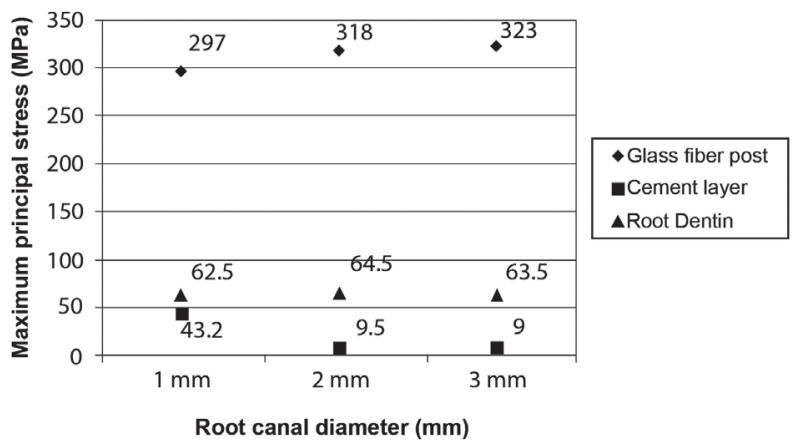

Figure 4- Maximum principal stress (MPa) for various root canal diameters $(1 \mathrm{~mm}, 2 \mathrm{~mm}$, and $3 \mathrm{~mm}$ ) with a constant glass fiber post diameter of $1 \mathrm{~mm}$ 
diameters with constant post diameters.

Increasing stress was observed in the glass fiber post with increasing canal diameter. The highest $\sigma_{\max }$ values were observed in model C3P1 (323 MPa), followed by C2P1 and C1P1 (Figure 4) in the incisal region of the post (Figure 5 ).

However, this behavior was not observed for the cement layer. On the contrary, the thinner the cementation interface (reduced canal diameter), the higher the $\sigma_{\max }$ level, as observed in models C1P1 (43 MPa), C2P1 (9.5 MPa), and C3P1 (9 MPa). The stress levels differ about $21 \%$ between the model with the highest stress and the model with the lowest stress (Figure 4).

The maximum $\sigma_{\max }$ was observed in the palatine surface, mainly in the middle third of the cement layer for C2P1 and C3P1, while in C1P1, the peak of stress was observed in the coronal area of both
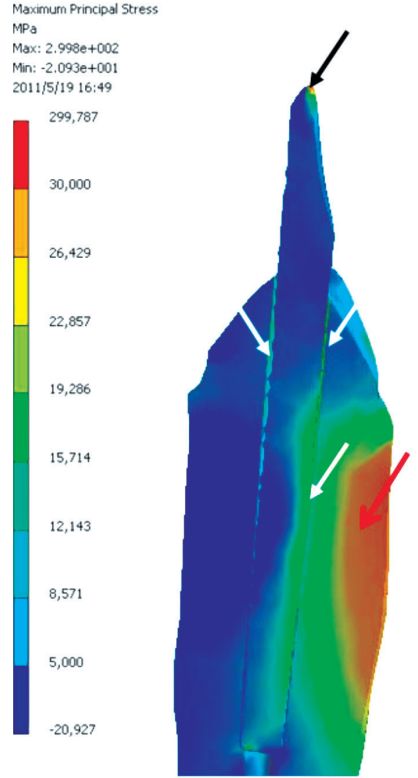

C1P1

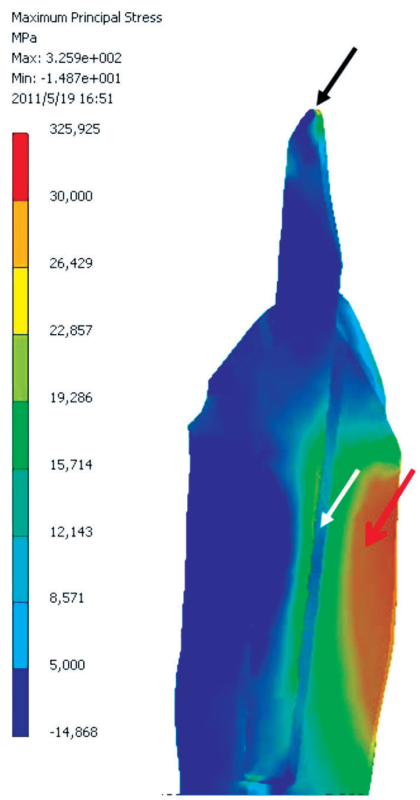

C3P1

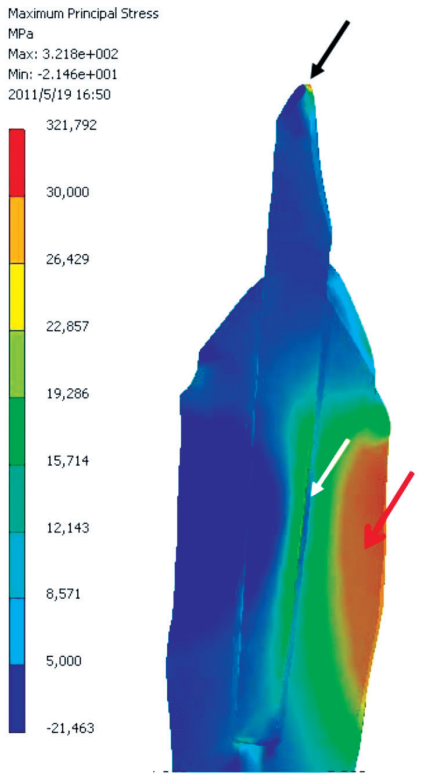

C2P1

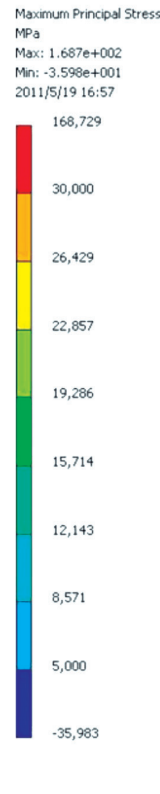

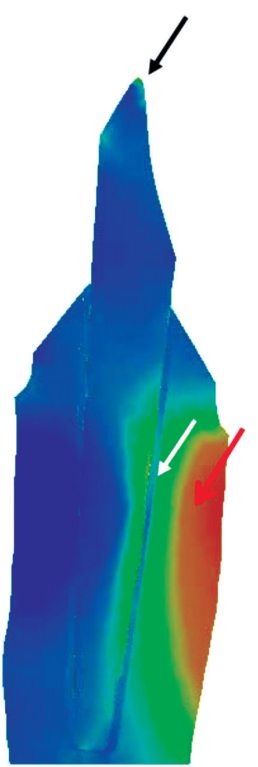

C3P2

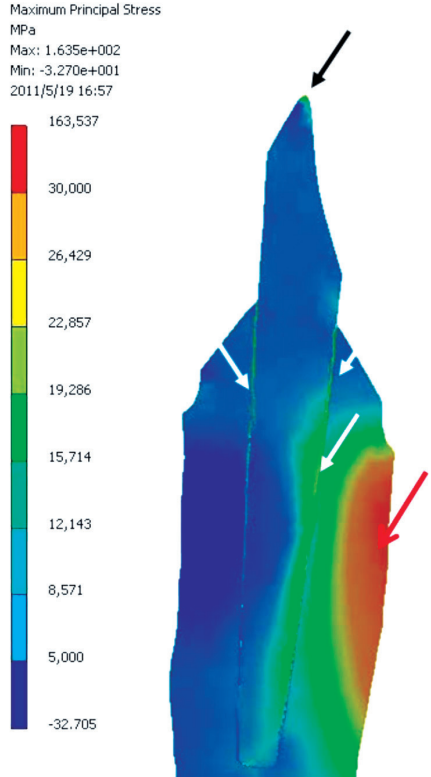

C2P2

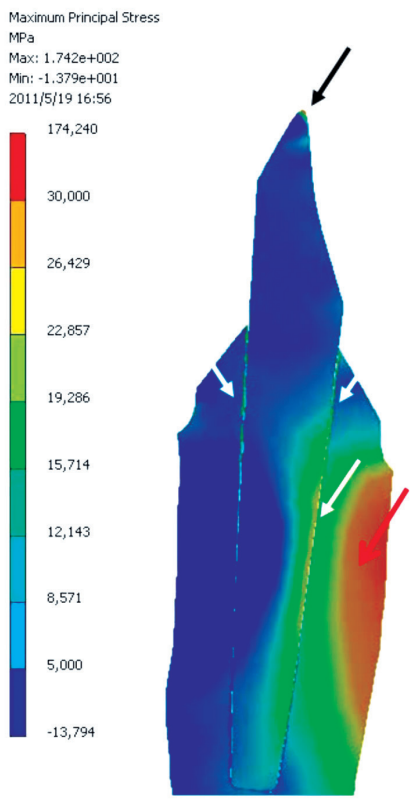

C3P3

Figure 5- Stress distribution in root-filled models. The stress distributions in the glass fiber posts were similar for all models (palatine surface in the coronal and middle thirds) and the peak of maximum principal stress occurred in the incisal area of the post (black arrow). Note that the stress distributions in the cement layer (white arrows) indicate the stress concentration in the cement line. For C2P1, C3P1, and C3P2, it occurs in the middle third in the palatine surface, while for C1P1, C2P2, and $\mathrm{C} 3 \mathrm{P} 3$, the stress concentrates at the middle and near the coronal thirds (white arrows). The stress peak in the dentin was concentrated among the coronal and middle thirds, mainly at the lingual dentin walls (red arrows) 


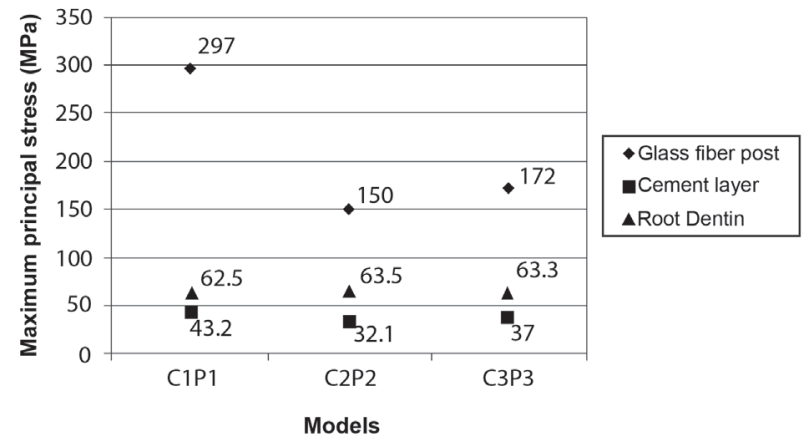

Figure 6- Maximum principal stress (MPa) for various glass fiber post diameters $(1 \mathrm{~mm}, 2 \mathrm{~mm}$, and $3 \mathrm{~mm}$ ) with a constant root canal diameter of $3 \mathrm{~mm}$. Comparing these models, the variation in post diameter did not play a role in stress levels occurring in the dentin. The higher stress levels were found for the $1 \mathrm{~mm}$ diameter, showing that a large discrepancy between the root canal and post diameters is less favorable for post integrity. Furthermore, the higher stress level on the cement layer occurred with a $3 \mathrm{~mm}$ post

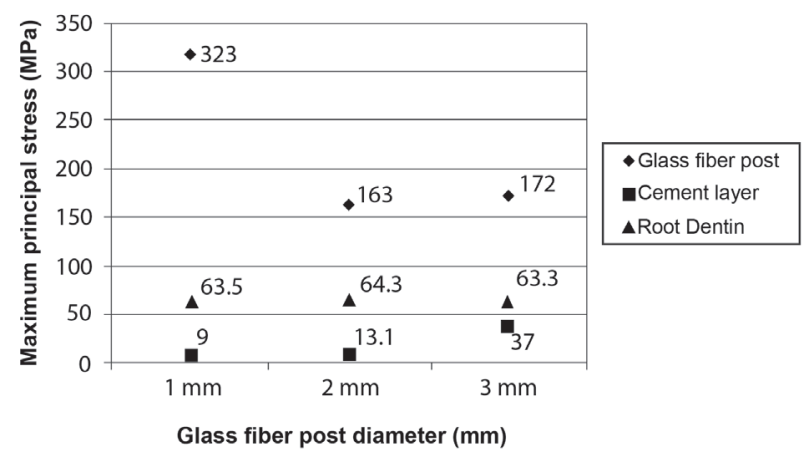

Figure 7- Maximum principal stress (MPa) for various glass fiber post diameters $(1 \mathrm{~mm}, 2 \mathrm{~mm}$, and $3 \mathrm{~mm}$ ) and root canal diameters $(1 \mathrm{~mm}, 2 \mathrm{~mm}$, and $3 \mathrm{~mm})$. The cement layer thickness is the same for all models. The intermediary preparation of the root canal restored with a post of intermediate thickness, as seen in C2P2, showed lower stress levels than the other models, mainly for the post and cement layer

the buccal and palatine surfaces (Figure 5).

\section{Variation of the glass fiber post diameter} $(1,2$, and $3 \mathrm{~mm})$ with a constant root canal diameter of $3 \mathrm{~mm}$

The structures of the post/cement interface exhibited different mechanical behaviors when we varied the glass fiber post diameter and kept the root canal diameter constant.

The results showed decreased stress with increasing glass fiber post diameter (Figure 6). However, although the difference was not as significant, the stress in C3P3 was higher than in C3P2 (Figure 6).
The highest stress level (323 MPa) occurred in C3P1; this was nearly twice the stress observed in C3P2 and C3P3.

Similarly, as the post diameter increased, so did the stress in the cement layer, which confirms that the thinner the cement layer, the higher the stress concentration on it (Figure 6).

The peak of stress occurred in the apical third of the buccal surface of the cement layer for C3P1 and $\mathrm{C} 3 \mathrm{P} 2$, while for C3P3 the peak of stress was found in the coronal third of the buccal and palatine surfaces.

\section{Variation of the root canal and the glass fiber post diameters}

Considering the use of a fiber post with a diameter similar to the canal lumen (C1P1, C2P2, and $\mathrm{C} 3 \mathrm{P} 3$ ), the conservative endodontic treatment with the greatest quantity of dental structure (C1P1) presented the worst mechanical behavior among the models with regard to stress concentration in the post and cement layer (Figure 7).

The lowest stress concentration was obtained by simulation of intermediary clinical conditions in $\mathrm{C} 2 \mathrm{P} 2$.

Unlike the structures of the glass fiber post and cement layer, stress in the remaining root dentin stayed nearly constant in all models, regardless of the amount of dentin or the glass fiber post diameters (Figures 4, 6, and 7). The highest stress levels on root dentin were found at the coronal region of the palatal surface for all models (Figure 7).

\section{DISCUSSION}

In the present study, regardless of the clinical situation simulated, the highest stress concentration was observed in the glass fiber post. Any discrepancy between the canal and post diameters was unfavorable, mainly in the coronal portion of the post where higher stress levels were found ${ }^{2,28}$.

Some authors explain this behavior by the transference of load from structures with a lower elastic modulus to structures with a higher elastic modulus, which favors stress concentration in the post $^{1}$, since the elastic modulus of the post ( 40 $\mathrm{GPa})$ is higher than that of dentin (18.6 GPa) and resin cement ( $8 \mathrm{GPa})$. Furthermore, the moment arm generated a greater concentration of tensile stresses at the lingual surface of the post.

Thus, the first hypothesis of this study was rejected, since stress generated in the post is inversely proportional to the diameter for large canals.

On the other hand, when the post and canal diameters were similar (C1P1, C2P2, C3P3), the stress values on the post were reduced in 
comparison to the previous situation. This suggests that thinner posts are more susceptible to damage than thicker posts, mainly when there is a difference between the root canal and post diameters.

The higher stress levels on the post may have resulted from the occlusal loading direction ${ }^{17}$. Considering that the forces in maxillary central incisors are oblique to the long dental axis during chewing, theoretically the post may undergo a virtual rotation with the fulcrum in the cervical region of the dentin, increasing the stress concentration on the post's external surface ${ }^{17}$.

Some studies have reported proper mechanical resistance of resin-reinforced GFP submitted to forces directed to the long axis of the reinforcing fibers ${ }^{9}$. However, under oblique loads, similar to the maxillary incisors, the resistance of the posts is reduced and may lead to fracture or debonding with excessive and repeated forces ${ }^{9}$.

In the present study, the simulation of a thicker cement layer seems to decrease the stress concentration on it. In a thin resin cement layer, there may be higher friction between the cement and dentin that prevents post displacement under loading and generates higher stress levels ${ }^{12}$. By contrast, in a thick resin cement layer, the deformation capacity of the cement layer is higher because of its lower elastic modulus, resulting in a lower stress concentration ${ }^{12}$. The thicker cement may absorb the stress generated in the restoration after oblique loading ${ }^{6}$.

On the other hand, Spazzin, et al. ${ }^{23}$ (2009) found that the thickness of the cement layer did not significantly influence stress concentration at the cement interface, although the stress was more evident when a thick cement layer was simulated. These authors reported that the elastic modulus of the cement layer is more important to the stress concentration in the root-filled teeth than the thickness of this layer.

Other authors evaluated a customized glass fiber post and non-customized glass fiber posts using $\mathrm{FEA}^{2}$ and in vitro ${ }^{13}$. Under incisal loading, the thickest cement layer present in the non-customized GFP models showed a lower stress level. However, they found higher interfacial stresses on the cement layer and coronal dentin when polymerization shrinkage was simulated for non-customized GFP models, showing the worst results for thicker cement layers ${ }^{2}$. These authors showed that the friction between post cement and root is higher when a thin cement film is present, improving post retention, and cement thickness plays an important role in the reduction of stress during cement curing. In addition, the other authors showed that customized GFP improved the post retention compared to non-customized posts ${ }^{13}$.

A thick cement layer may jeopardize the longevity of the restorations since adhesive failures are more common in the cementation interface after cyclic loading ${ }^{12,24}$. The positioning of the maxillary central incisor allows repetitive stress induction in the post, compression in the buccal surface, and tensile stress in the palatal surface ${ }^{26}$.

Literature reports that the ultimate tensile strength (UTS) of resin cement with an elastic modulus of $8 \mathrm{GPa}$ is about $12 \mathrm{MPa}^{15}$. Simulations of thin cement layers (C1P1, C2P2, and C3P3) generated stresses almost three times higher than the maximum rupture load, reaching values of about $43 \mathrm{MPa}$. However, the stresses did not reach the limit for cement rupture in the simulations with thicker cement layers.

The increasing canal diameter did not increase the stress surrounding the root dentin, which maintained constant in all models. Similarly, when the post diameter was increased, stress on the remaining root structure did not increase. Following these results, the second hypothesis was rejected. However, some authors found that large-diameter posts decrease stress in the remaining root because the larger contact surface with the post improves stress dispersion and distribution ${ }^{18}$.

Although the stresses achieved the limit of maximum tensile load for dentin in all models (40 to $60 \mathrm{MPa})^{14}$, roots with less dentin do not support loads in the same way as roots with more dentin. The literature clearly shows that the greater the volume of dentin, the greater the fracture resistance of the remaining structure ${ }^{30}$. Accordingly, the models with lower amounts of dentin (C3P1, C3P2, and C3P3) are more prone to failure in the root dentin than the models with greater amounts of residual dentin (C1P1, C2P1 and C2P2).

Additional information has been presented concerning the influence of root canal and glass fiber post diameters on stress distribution in a maxillary central incisor; however, direct comparison between these results and clinical conditions should be made with caution since all structures were considered as bonded, isotropic materials in this study. This situation may influence the results, since failures can initiate many defects in the cementation interface. Furthermore, although the models were built based on micro-CT data, no experimental in vitro validation was performed. Further laboratory and clinical studies are necessary to confirm the present results.

\section{CONCLUSION}

Within the limitations of the present study, it is possible to conclude that the greatest discrepancy between root canal and post diameters is favorable for stress concentration at the post surface. The amount of dentin remaining after the different root canal preparations did not increase the stress levels 
on the root.

\section{ACKNOWLEDGEMENTS}

This study was supported by the São Paulo Research Foundation (FAPESP, Brazil, grant no. 2008/00209-9) and by the Coordination of Higher Education and Graduate Training (CAPES, Brazil, grant no. BEX 2325-05-5).

\section{REFERENCES}

1- Akkayan B, Gülmez T. Resistance to fracture of endodontically treated teeth restored with different post systems. J Prosthet Dent. 2002;87:431-7.

2- Anchieta RB, Rocha EP, Almeida EO, Freitas AC Jr, Martin M Jr, Martini AP, et al. Influence of customized composite resin fibreglass posts on the mechanics of restored treated teeth. Int Endod $\mathrm{J}$. 2012;45:146-55.

3- Anchieta RB, Rocha EP, Ko CC, Sundfeld RH, Martin Junior $M$, Archangelo $C M$. Localized mechanics of dentin self etching adhesive system. J Appl Oral Sci. 2007;15:321-6.

4- Archangelo $\mathrm{CM}$, Rocha EP, Anchieta RB, Martin M Jr, Freitas $A C \mathrm{Jr}$, Ko CC, et al. Influence of buccal cusp reduction when using porcelain laminate veneers in premolars. A comparative study using 3-D finite element analysis. J Prosthodont Res. 2011;55:221-7.

5- Asmussen E, Peutzfeldt A, Sahafi A. Finite element analysis of stresses in endodontically treated, dowel-restored teeth. J Prosthet Dent. 2005;94:321-9.

6- Ausiello P, Apicella A, Davidson CL. Effect of adhesive layer properties on stress distribution in composite restorations - a 3D finite element analysis. Dent Mater. 2002;18:295-303.

7- Barjau-Escribano A, Sancho-Bru JL, Forner-Navarro L, Rodríguez-Cervantes PJ, Pérez-Gónzález A, Sanchez-Marín FT. Influence of prefabricated post material on restored teeth: fracture strength and stress distribution. Oper Dent. 2006;31:47-54.

8- Boschian Pest L, Guidotti S, Pietrabissa R, Gagliani M. Stress distribution in a post-restored tooth using the three dimensional finite element method. J Oral Rehabil. 2006;33:690-7.

9- Christensen GJ. Post concepts are changing. J Am Dent Assoc. 2004;135:1308-10.

10- Cury AH, Goracci C, Lima Navarro MF, Carvalho RM, Sadek FT, Tay FR, et al. Effect of hygroscopic expansion on the push-out resistance of glass ionomer-based cements used for the luting of glass fiber posts. J Endod. 2006;32:537-40.

11- Dietschi D, Duc O, Krejci I, Sadan A. Biomechanical considerations for the restoration of endodontically treated teeth: a systematic review of the literature, Part II (Evaluation of fatigue behavior, interfaces, and in vivo studies). Quintessence Int. 2008;39:117-29.

12- Egilmez F, Ergun G, Cekic-Nagas I, Vallittu PK, Lassila LV. Influence of cement thickness on the bond strength of toothcolored posts to root dentin after thermal cycling. Acta Odontol Scand. 2013;71:175-82.

13- Faria-e-Silva AL, Pedrosa-Filho CF, Menezes MS, Silveira DM, Martins LR. Effect of relining on fiber post retention to root canal. J Appl Oral Sci. 2009;17:600-4.
14- Lertchirakarn V, Palamara JEA, Messer HH. Anisotropy of tensile strength of root dentin. J Dent Res. 2001;80:453-6.

15- Liu HL, Lin CL, Sun MT, Chang YH. Numerical investigation of macro- and micro-mechanics of a ceramic veneer bonded with various cement thicknesses using the typical and submodeling finite element approaches. J Dent. 2009;37:141-8.

16- Martini AP, Anchieta RB, Rocha EP, Freitas Junior AC, Almeida $\mathrm{EO}$, Sundfeld $\mathrm{RH}$, et al. Influence of voids in the hybrid layer based on self-etching adhesive systems: a 3-D FE analysis. J Appl Oral Sci. 2009;17:19-26.

17- Meira JB, Espósito CO, Quitero MFZ, Poiate IA, Pfeifer CS, Tanaka $C B$, et al. Elastic modulus of posts and the risk of root fracture. Dent Traumatol. 2009;25:394-8.

18- Okamoto K, Ino T, Iwase N, Shimizu E, Suzuki M, Satoh G, et al. Three-dimensional finite element analysis of stress distribution in composite resin cores with fiber posts of varying diameters. Dent Mater J. 2008;27:49-55.

19- Oliveira FG, Anchieta RB, Rahal V, Alexandre RS, Machado LS, Sundefeld $M L$, et al. Correlation of the hybrid layer thickness and resin tags length with the bond strength of a self-etching adhesive system. Acta Odontol Latinoam. 2009;22:177-81.

20- Pegoretti A, Fambri L, Zappini G, Bianchetti M. Finite element analysis of a glass fibre reinforced composite endodontic post. Biomaterials. 2002;23:2667-82.

21- Rocha EP, Anchieta RB, Freitas AC Jr, Almeida EO, Cattaneo PM, Chang Ko C. Mechanical behavior of ceramic veneer in zirconia-based restorations: a 3-dimensional finite element analysis using microcomputed tomography data. J Prosthet Dent. 2011;105:14-20.

22- Sorrentino R, Aversa R, Ferro V, Auriemma T, Zarone F, Ferrari $M$, et al. Three-dimensional finite element analysis of strain and stress distributions in endodontically treated maxillary central incisors restored with different post, core and crown materials. Dent Mater. 2007;23:983-93.

23- Spazzin AO, Galafassi D, Meira-Júnior AD, Braz R, Garbin $C A$. Influence of post and resin cement on stress distribution of maxillary central incisors restored with direct resin composite. Oper Dent. 2009;34:223-9.

24- Tait CM, Ricketts DN, Higgins AJ. Weakened anterior roots intraradicular rehabilitation. Br Dent J. 2005;198:609-17.

25- Tay FR, Loushine RJ, Lambrechts P, Weller RN, Pashley DH. Geometric factors affecting dentin bonding in root canals: a theoretical modeling approach. J Endod. 2005;31:584-9.

26- Toksavul S, Toman M, Uyulgan B, Schmage P, Nergiz I. Effect of luting agents and reconstruction techniques on the fracture resistance of prefabricated post systems. J Oral Rehabil. 2005;32:433-40.

27- Tortopidis D, Lyons MF, Baxendale RH, Gilmour WH. The variability of bite force measurement between sessions, in different positions within the dental arch. J Oral Rehabil. 1998;25:681-6. 28- Watanabe MU, Anchieta RB, Rocha EP, Kina S, Almeida EO, Freitas AC Jr, et al. Influence of crown ferrule heights and dowel material selection on the mechanical behavior of root-filled teeth: a finite element analysis. J Prosthodont. 2012;21:304-11. 29- Yang HS, Lang LA, Guckes AD, Felton DA. The effect of thermal change on various dowel-and-core restorative materials. J Prosthet Dent. 2001;86:74-80.

30- Zogheib LV, Pereira JR, Valle AL, Oliveira JA, Pegoraro LF. Fracture resistance of weakened roots restored with composite resin and glass fiber post. Braz Dent J. 2008;19:329-33. 